\title{
Contributions of Vegetation Greening and Climate Change to Evapotranspiration Trend after Large-Scale Vegetation Restoration on the Loess Plateau, China
}

\author{
Shuo Wang ${ }^{1,2}$, Chenfeng Cui ${ }^{1,2, *}$ and Qin Dai ${ }^{1}$ \\ 1 College of Water Resources and Architecture Engineering, Northwest A\&F University, \\ Yangling 712100, China; wangshuox@139.com (S.W.); dai-qin@163.com (Q.D.) \\ 2 Key Laboratory of Agricultural Soil and Water Engineering in Arid and Semiarid Areas of Ministry \\ of Education, Northwest A\&F University, Yangling 712100, China \\ * Correspondence: cuichenfeng@163.com
}

Citation: Wang, S.; Cui, C.; Dai, Q. Contributions of Vegetation Greening and Climate Change to

Evapotranspiration Trend after Large-Scale Vegetation Restoration on the Loess Plateau, China. Water 2021, 13, 1755. https://doi.org/10.3390/ w13131755

Academic Editor: Guido D’Urso

Received: 10 May 2021

Accepted: 18 June 2021

Published: 25 June 2021

Publisher's Note: MDPI stays neutral with regard to jurisdictional claims in published maps and institutional affiliations.

Copyright: (c) 2021 by the authors. Licensee MDPI, Basel, Switzerland. This article is an open access article distributed under the terms and conditions of the Creative Commons Attribution (CC BY) license (https:// creativecommons.org/licenses/by/ $4.0 /)$.

\begin{abstract}
Since the early 2000s, the vegetation cover of the Loess Plateau (LP) has increased significantly, which has been fully recorded. However, the effects on relevant eco-hydrological processes are still unclear. Here, we made an investigation on the changes of actual evapotranspiration $\left(\mathrm{ET}_{\mathrm{a}}\right)$ during 2000-2018 and connected them with vegetation greening and climate change in the LP, based on the remote sensing data with correlation and attribution analysis. Results identified that the

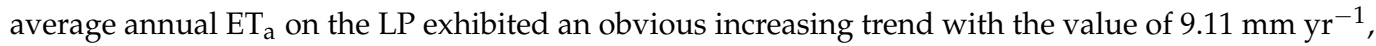
and the annual $\mathrm{ET}_{\mathrm{a}}$ trend was dominated by the changes of $\mathrm{ET}_{\mathrm{a}}$ in the third quarter (July, August, and September). The future trend of $\mathrm{ET}_{\mathrm{a}}$ was predicted by the Hurst exponent. Partial correlation analysis indicated that annual $\mathrm{ET}_{\mathrm{a}}$ variations in $87.8 \%$ regions of the LP were controlled by vegetation greening. Multiple regression analysis suggested that the relative contributions of potential evapotranspiration $\left(\mathrm{ET}_{\mathrm{p}}\right)$, precipitation, and normalized difference vegetation index (NDVI), to the trend of $\mathrm{ET}_{\mathrm{a}}$ were $5.7 \%,-26.3 \%$, and $61.4 \%$, separately. Vegetation greening has a close relationship with the Grain for Green (GFG) project and acts as an essential driver for the long-term development trend of water consumption on the LP. In this research, the potential conflicts of water demanding between the natural ecosystem and social-economic system in the LP were highlighted, which were caused by the fast vegetation expansion.
\end{abstract}

Keywords: evapotranspiration; NDVI; climate change; partial correlation analysis; contribution; loess plateau

\section{Introduction}

Evapotranspiration (ET), as a key link between surface energy balance and water balance, is an important factor connecting the ecological environment and hydrological cycle [1]. Terrestrial ET processes may significantly transform on multiple spatial and temporal scales with the changes of land use and climate [2], which impacts regional vegetation growth, water cycle, and the climate change feedback, particularly in arid and semiarid areas [3]. Additionally, the variation of the regional water cycle can be recognized by the long-term trend of ET [4]. Consequently, a comprehensive understanding of the interrelation between land-use changes, climate change, and the ET trend is critical for ecosystem conservation and water resource management.

The Loess Plateau (LP) is located at the junction of northwest and northern China and belongs to the arid continental monsoon climate zone, where about $85 \%$ precipitation is expended by ET [5]. Since the implementation of the Grain for Green (GFG) project, LP has come through considerable land-use changes under large-scale vegetation restoration, whose significant characteristic was the massive transformation from sparse vegetation and farmlands to grassland or shrubbery [6]. During 1999-2010, the GFG project had transformed rain-fed farmland about $16,000 \mathrm{~km}^{2}$ into grassland and forest [7]. The increasing 
trend of the normalized difference vegetation index (NDVI) has been significant in the LP since 2000 [8]. As a result, the vegetation coverage of the LP has remarkably increased from $31.6 \%$ in 1999 to $59.6 \%$ in 2013 [9]. During this period, the change of climate is gradually occurring, with wetter and slightly cooling trends rather than the warming-drying trend before the late 1990s [10]. Therefore, the Plateau ecosystem is significantly influenced by human activities and climate change [11], whose indirect or direct impacts on the hydrologic cycle are still indistinct on multiple spatial-temporal scales.

Land-use changes can affect the ET process through changing surface roughness, interception, and albedo [12]. For the inter-annual trend of ET, the change of climate variable on the long-term scale is also an important driving factor [13]. The early researches on the responses of ET to vegetation change were normally based on the field experiment, which was by means of observing the distinction of site scale ET under different climate conditions or different vegetation cover conditions to confirm the impacts of climate changes and vegetation on ET evolution process [14]. A field experiment is an essential approach in revealing the interrelated mechanism of soil, vegetation, and atmosphere. However, the field scale brings uncertainty of the study universality. In different areas, the results of field experiments are usually inconsistent because of the limitation on specific vegetation types, soil types, and climatic conditions.

Consequently, hydrologic models based on the physical are usually used by many researchers in order to make clear the influences of land use and climate variations in ET, groundwater, soil water, and runoff under different scenes $[15,16]$. Such physically-based hydrological models are effective for the estimate of regionally hydrologic responses under different land surface conditions and climate. However, there are some noticeable disadvantages in model validation and calibration such as too many parameters, complicated model structures, uncertainty, and time-consuming. Additionally, in other studies, the impacts of underlying surface types and climate changes on the hydrological processes were usually assessed by the empirical models based on the Budyko framework or water balance by some scholars [17-19]. Using these empirical models, the uncertainties that existed in the models based on physics are avoided and therefore an effective and simple method for attribution analysis is provided [20,21]. However, due to their characteristic application based on the annual and basin-scale, it is normally not thought that they can obtain the spatial-temporal distributions of ET.

A lot of field experiments have shown that the response and corresponding mechanism of ET to the variation of vegetation conditions are different based on the vegetation composition and type [22]. In addition, the response may vary with various spatial scales [23]. Traditional empirical modeling methods or field experiments cannot fully reflect the response mechanism based on vegetation types and spatial scales. With the development of satellite technology, remote sensing provides a wide range of spatial coverage of land surface features and high spatial and temporal resolution [24]. Therefore, more and more research is utilizing remote sensing based on remote sensing retrievals or ET models to solve the effect of vegetation coverage changes on the ET process. For example, depending on the ET dataset based on satellite estimation, Li et al. [25] researched the impacts of climate variation and land surface pattern on actual ET in the Tarim River, China from 2002 to 2012.

Previous studies have indicated that with the increase of vegetation coverage in the LP, the regional ET has also obviously changed [26]. Additionally, the complexity of understanding and quantifying spatiotemporal patterns and drivers of ET is enhanced by the interaction between climate variation and vegetation greening. However, the impacts of climate variation on vegetation growth were usually ignored due to the fact that many researchers only studied the impacts of vegetation greening and climate change on ET. Consequently, the contribution of human activities to ET variations may be overestimated. In addition, many studies based on remote sensing focus on the response of ET to the vegetation restoration or other influencing variables, but few studies have investigated the process and mechanisms of historical ET, although understanding the evolution mecha- 
nism of ET is essential for estimating terrestrial ecosystems and land surface-atmosphere interactions and making clear its responses to land cover changes and climate change.

In the study, the precipitation data can be obtained from meteorological stations, and the calculation of vegetation index is relatively simple. However, the potential ET data is often based on the traditional method of evaporating dish measurement and is limited by natural and man-made conditions. It is difficult to obtain large-area ET observation and estimation. Remote sensing technology, because of its large-area, dynamic and rapid access to surface conditions, has had rapid development in recent years, so that large-scale non-uniform land surface ET research has made great progress. For example, Jung et al. [27] provided a data-driven, spatially explicit estimate of global terrestrial ET from 1982 to 2008; the Numerical Terra Dynamic Simulation Group of Montana University researched and developed the global MODIS ET data set, which has been widely used in the study of ET with high spatial and temporal resolution. Liu et al. [28,29] used hydrological and meteorological data to verify the applicability of MODIS ET products in Asia and China, and good results were obtained.

On this basis, the hydrological responses of vegetation greening and climate change in the LP were analyzed by using MOD16 products and NDVI satellite remote sensing data, combined with the meteorological data of 98 national meteorological stations inside and outside the LP from 2000 to 2018. This study is aimed at (1) analyzing the temporal and spatial changes and evolution mechanisms of ET; (2) identifying the leading driver that controls the inter-annual changes of ET; (3) quantitatively distinguishing the contribution of climate and vegetation changes to ET trends.

\section{Materials and Methods}

\subsection{Study Area}

The Loess Plateau is at the junction of northwest and northern China $\left(33^{\circ} \sim 42^{\circ} \mathrm{N}\right.$, $100^{\circ} \sim 114^{\circ} \mathrm{E}$ ), covering an area of $64,000 \mathrm{~km}^{2}$. The average altitude of LP is $1398 \mathrm{~m}$. It is one of the four major plateaus in China and also the largest loess plateau in the world (Figure 1), spanning west from the Qinghai Province Sun Moon Mountain, east to Henan Province Taihang Mountain, south Qinling, and north to the Great Wall. The main coverage includes all regions of Shanxi Province, as well as some regions of Qinghai, Shaanxi, Inner Mongolia, Gansu, Ningxia, Henan, and other provinces, a total of 7 provinces (autonomous regions), 46 places (league, state, city), and 282 counties (flags, cities, districts). The area is in the semi-arid and arid transition zone, located on the edge of the warm temperate continental monsoonal climate area, having more prominent mainland and monsoon instability. Being cold and dry in spring and winter, hot and rainy in summer and autumn, it has an average annual precipitation of $150-750 \mathrm{~mm}$ and an average annual temperature of $3.6-14.3^{\circ} \mathrm{C}$ over the whole Loess Plateau. From northwest to southeast, the vegetation types of the Loess Plateau are desert, desert steppe, typical steppe, and forest-steppe with a gradual increase of leaf area index.

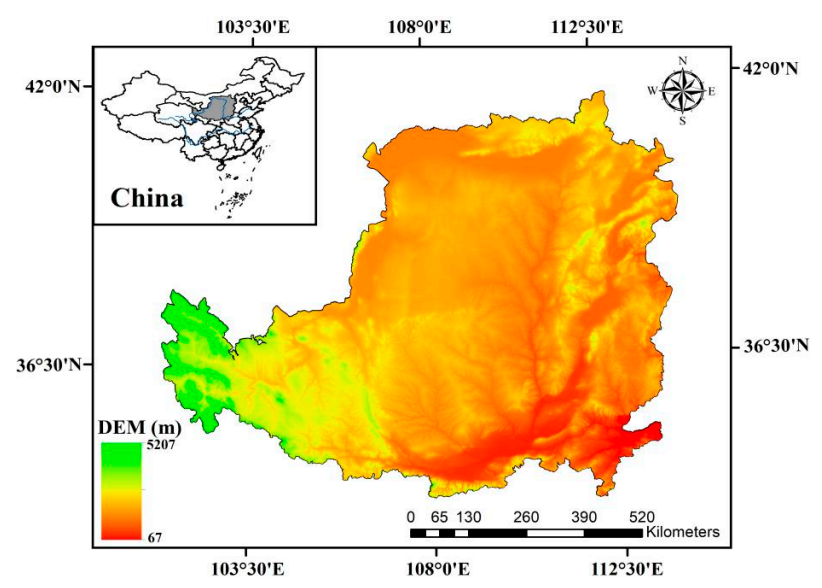

Figure 1. Location of the Loess Plateau. 


\subsection{Data}

MOD16 global land surface evapotranspiration data set is one of the NASA/EOS projects, its accuracy of using satellite remote sensing data to retrieve global land evapotranspiration has been verified in many aspects. It has been widely used to analyze soil moisture, water, and energy balance in a watershed. Based on the long-term evapotranspiration data obtained from the MOD16 product, the effects of meteorology, land cover type changes, and ecosystem disturbances on regional water resource changes can be quantified. In MOD16, a class 4 product of the MODIS series, after geometric correction and radiation correction, each pixel in the data is accompanied by geocoding, reflectivity, and radiance information, which can not only provide characteristic parameters related to evapotranspiration but also have the characteristics of high time resolution (up to 8-day) and low error (error less than 1 pixel), etc.

In the study, the surface evaporative monthly synthesis product set (MOD16A2), including surface evapotranspiration $\left(\mathrm{ET}_{\mathrm{a}}\right)$ and potential evapotranspiration $\left(\mathrm{ET}_{\mathrm{p}}\right)$ with 8-day temporal composite at $500 \mathrm{~m}$ spatial resolution from 2000 to 2018 in the LP, were obtained from the Level 1 and Atmosphere Archive and Distribution System (LAADS) DAAC of National Aeronautics and Space Administration (NASA). The algorithm used for the MOD16A2 product is based on the Penman-Monteith equation [30]. It is noted that for the spatial areas in the LP such as city, water, glacier, and bare land, data cannot be obtained in the study. The basic information of the data was shown in Table 1. Firstly, the original hierarchical data HDF formats were converted to GeoTiff format by using the MRT projection conversion tool, transforming SIN projection into WGS-1984/geographic longitude and latitude coordinate system and splicing the image. Then, based on the data provided from the NASA website, eliminate invalid values and restore true values. Finally, the actual evapotranspiration $\left(E_{a}\right)$ and potential evapotranspiration $\left(E_{p}\right)$ in each year and month of the study area were extracted by vector clipping through ArcGIS software.

Table 1. Attribution of MOD16A2 remote sensing data.

\begin{tabular}{ccrrrr}
\hline Remote Sensing Data & Satellite Orbit & Time Span & Spatial Resolution & $\begin{array}{c}\text { Temporal } \\
\text { Resolution }\end{array}$ \\
\hline & h23v04/h23v05 & & & Data Sources \\
MOD16A2 & h23v04/h23v05 & January 2000-December 2018 & 500 m & NASA & \\
\hline
\end{tabular}

NDVI datasets were obtained from the Institute of Tibetan Plateau Research, Chinese Academy of Sciences. It is the SPOT VEGETATION NDVI satellite remote sensing dataset based on continuous time series, generated by the maximum value synthesis method since 1998. The distribution and changes of vegetation coverage in all regions of the country at spatial-temporal scale are reflected by this dataset effectively. In the study, NDVI grid files with 10-day temporal composite at $1000 \mathrm{~m}$ spatial resolution from 2000 to 2018 inside the Loess Plateau were obtained by splicing and recasting.

Meteorological data, including the temperature and precipitation data of the LP from 2000 to 2018, were obtained from the National Earth System Science Data Center of China. These data were strictly screened to eliminate the abnormal data, and then the univariate linear regression method was used to calculate the interpolation for the meteorological values of individual missing measurements. After a comparison with other interpolation methods such as ordinary kriging (OK) and empirical Bayesian kriging (EBK) [31-33], the precipitation data were gridded by inverse distance weighted (IDW) [34] with the spatial resolution of $1 \mathrm{~km}$, which was more efficient and accurate in the cases of dealing a lot of data on the large region.

\subsection{Methodology}

The spatial patterns of the variables were determined by the annual mean of them from 2000 to 2018 in the LP. 
The slope of the univariate linear regression model [35] determined the trends of ET, NDVI, and climate variables:

$$
k=\frac{n \sum_{m=1}^{n} m \times X_{m}-\sum_{m=1}^{n} m \sum_{m=1}^{n} X_{m}}{n \sum_{m=1}^{n} m^{2}-\left(\sum_{m=1}^{n} m\right)^{2}}
$$

where $k$ is the slope of the univariate linear regression model; $n$ represents the span of the year; $m$ represents the order of year, and $X_{m}$ represents the variable value for the mth year. The larger value of $k$ is, the more significant the changing trend is.

Then we calculated the Hurst exponent [36] to analyze the self-similarity and longterm dependence of $\mathrm{ET}_{\mathrm{a}}$ in order to forecast its value trend in the existing circumstances:

For $\{X(t)\}(t=1,2, \cdots, n)$, its mean of time sequence:

$$
\bar{X}_{(\tau)}=\frac{1}{\tau} \sum_{t=1}^{\tau} X_{(\tau)} \quad(\tau=1,2, \cdots, n)
$$

Cumulative deviation:

$$
X_{(t, \tau)}=\sum_{t=1}^{\tau}\left(X_{(\tau)}-\bar{X}_{(\tau)}\right) \quad(1 \leq \tau \leq 2)
$$

Range sequence:

$$
R_{(\tau)}=\max _{1 \leq t \leq \tau} X_{(t, \tau)}-\min _{(t, \tau)} \quad(\tau=1,2, \cdots, n)
$$

Standard deviation sequence:

$$
S_{(\tau)}=\left[\frac{1}{\tau} \sum_{t=1}^{\tau}\left(X_{(\tau)}-\bar{X}_{(\tau)}\right)^{2}\right]^{\frac{1}{2}} \quad(\tau=1,2, \cdots, n)
$$

Hurst exponent calculation:

$$
\frac{R_{(\tau)}}{S_{(\tau)}}=(c \tau)^{H}
$$

where $X$ presents $\mathrm{ET}_{\mathrm{a}}$ and $c$ is a constant, the Hurst empirical formula can be obtained by taking the logarithm on both sides of Equation (6). The Hurst exponent $(H)$ is obtained by using the Hurst empirical formula based on time series correction, and $H$ represents the trend change with time series. When $0.5<H<1$, it shows the future change trend is consistent with the past, and the closer to 1 , the stronger the consistent tendency is; when $H=0.5$, it indicates that the future change trend is random and cannot be predicted; when $0<H<0.5$, it indicates that the future change trend is opposite to the past, and the closer to 0 , the stronger the anti consistency is [37].

To determine the dominant driving forces controlling the inter-annual changes of $\mathrm{ET}_{\mathrm{a}}$, the partial correlation analysis between $\mathrm{ET}_{\mathrm{a}}$ and NDVI, $\mathrm{ET}_{\mathrm{p}}$, and $\mathrm{P}$ were conducted on the pixel scale. For each pixel, the variable with the highest partial correlation coefficient was judged as the dominant driving factor.

The influence of each factor on $\mathrm{ET}_{\mathrm{a}}$ change was quantitatively differentiated by multiple regression, and the relative contribution rate of each factor to $\mathrm{ET}_{\mathrm{a}}$ change was identified. The significant levels of independent variables entering and moving out of multivariate regression models were set to 0.05 and 0.1 , respectively. In order to identify the relative contribution rate of each factor to $\mathrm{ET}_{\mathrm{a}}$ change, we firstly standardize the data by the z-score standardized method. Then, the regression equation of the standardized data sequence is 
obtained by regression analysis. According to the following formula, the contribution rate of each variable change to the dependent variable change can be calculated [38]:

$$
\begin{gathered}
Y_{s}=a X_{1 s}+b X_{2 s}+c X_{3 s} \ldots \\
\eta_{1}=\frac{a}{|a|+|b|+|c|+\ldots} \\
\eta_{2}=\frac{a \Delta X_{1 s}}{\Delta Y_{s}}
\end{gathered}
$$

where $Y_{s}$ is the standard value of dependent variables; $X_{1 s}, X_{2 s}, X_{3 s} \ldots$ is the standard values of independent variables; and $a, b, c$ is the regression coefficient after sequence standardization; $\eta_{1}$ represents the relative contribution rate of $X_{1}$ change to $Y$ change; $\eta_{2}$ represents the actual contribution rate of $X_{1}$ change to $Y$ change; $\Delta Y_{s}$ is the variation of $Y_{s}$ change; $\Delta X_{1}$ is the variation of $X_{1 s}$.

The specific technology roadmap is as Figure 2:

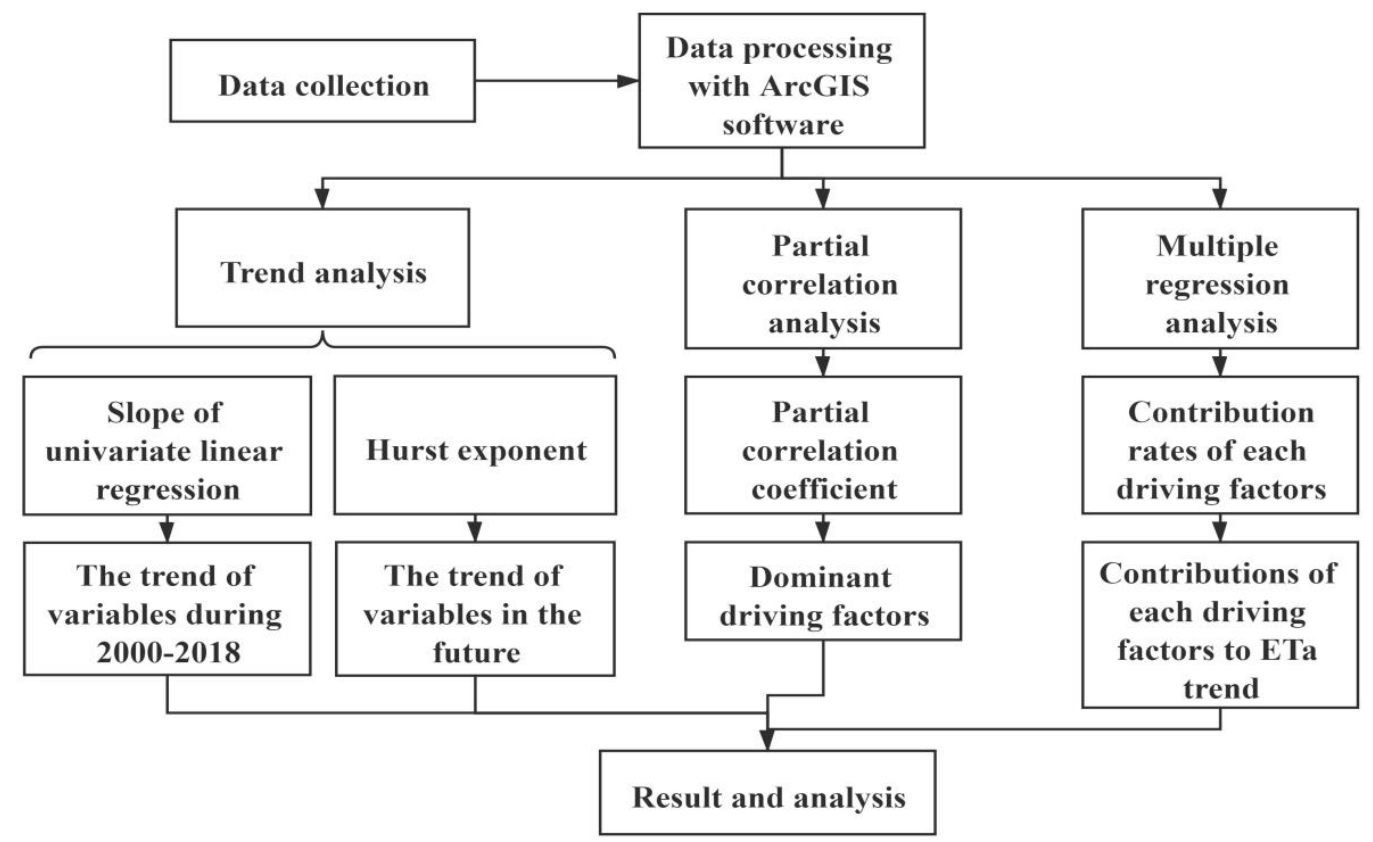

Figure 2. Technology roadmap.

\section{Results and Analysis}

\subsection{Spatial Patterns of $E T_{a}, E T_{p}, N D V I$, and Precipitation}

With certain vegetation and climate conditions in the Loess Plateau, precipitation and available energy which is represented by $\mathrm{ET}_{\mathrm{p}}$ are the main driving factors of long-term annual $\mathrm{ET}_{\mathrm{a}}$ [39]. As shown in Figure 3a, there was a large spatial variability for annual $\mathrm{ET}_{\mathrm{a}}$ on the LP, which gradually increased from northwest to southeast areas, ranging from $139 \mathrm{~mm}$ to $936 \mathrm{~mm}$. Compared with the spatial distribution of annual precipitation as shown in Figure 3d, the spatial pattern of $\mathrm{ET}_{\mathrm{a}}$ was consistent with it on the whole. Multiyear averaged $\mathrm{ET}_{\mathrm{a}}(370 \mathrm{~mm})$ shared about $80 \%$ of the corresponding precipitation $(466 \mathrm{~mm})$. This result made clear that evaporation was the way for most of the precipitation to return to the atmosphere eventually and that precipitation on the multi-year scale mostly regulated the changes of annual $\mathrm{ET}_{\mathrm{a}}$. For the spatial pattern of annual $\mathrm{ET}_{\mathrm{a}}$, the NDVI (Figure 3c) was more consistent with it $(\mathrm{r}=0.66)$ by comparison with that of the precipitation and it indicated that the annual $\mathrm{ET}_{\mathrm{a}}$ was mainly regulated by different conditions of vegetation. As shown in Figure $3 b$, the spatial pattern of annual $\mathrm{ET}_{\mathrm{p}}$ was obviously contrary to that of $\mathrm{ET}_{\mathrm{a}}(\mathrm{r}=-0.48)$, and the value of annual $\mathrm{ET}_{\mathrm{p}}$ generally decreased from northwest to southeast areas. 

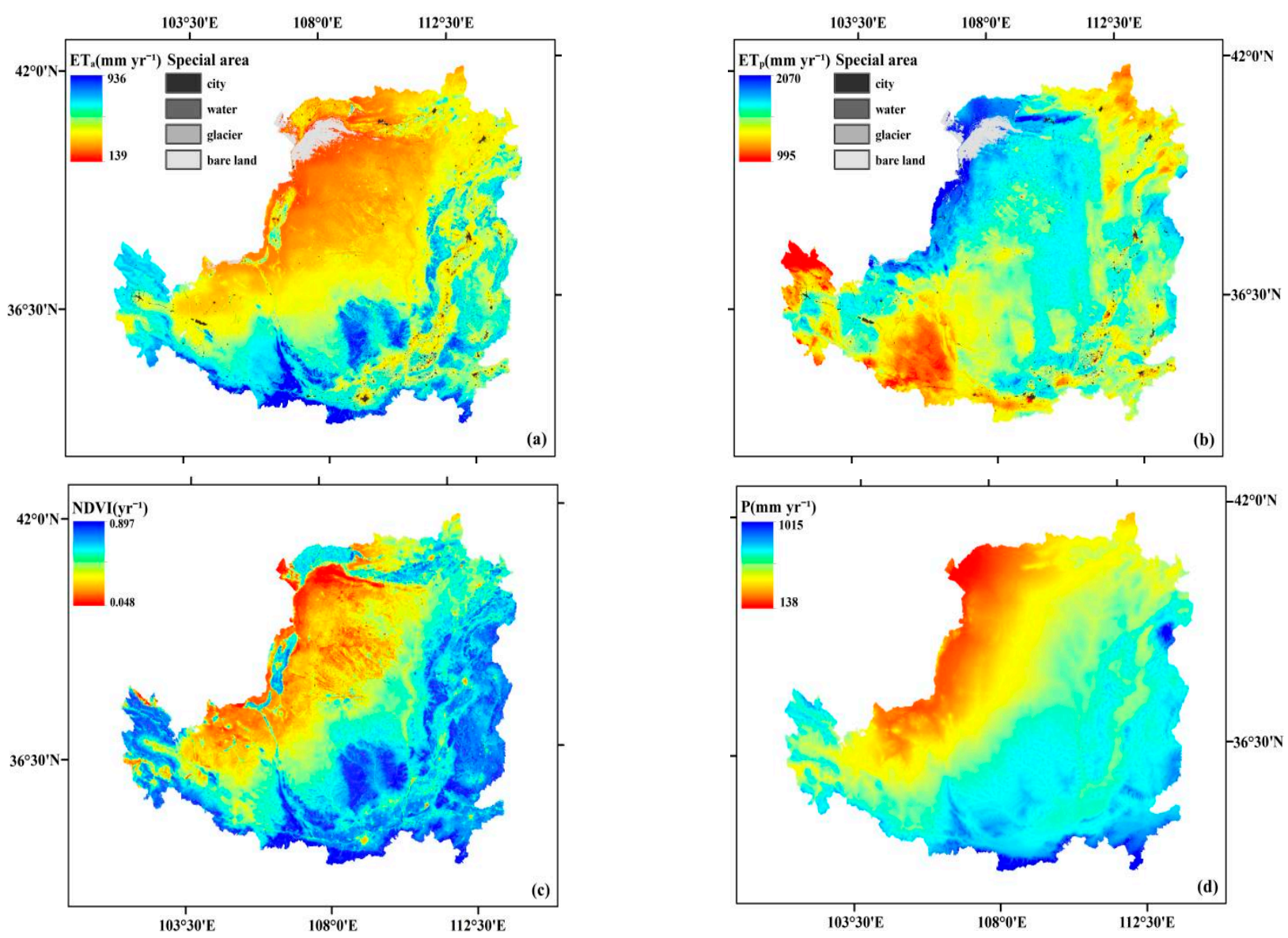

Figure 3. Spatial patterns of mean annual actual evapotranspiration ET $\left(\mathrm{ET}_{\mathrm{a}}\right)(\mathbf{a})$, potential ET $\left(\mathrm{ET}_{\mathrm{p}}\right)(\mathbf{b})$, normalized difference vegetation index (NDVI) (c), precipitation (P) (d) from 2000 to 2018 in the Loess Plateau (LP).

\subsection{Spatial and Temporal Changes of Climate, NDVI, and ET}

For the processes of the regional eco-hydrological cycle, climate conditions and human activities are the important driving factors. Changes in climate variables may have a significant effect on the water consumption of vegetation. Human activities, which can indirectly and even directly impact the growth of natural vegetation by means of agricultural management and ecological restoration, also has a significant influence on the processes of eco-hydrological evolution.

\subsubsection{Change in Climate}

According to the previous studies, the climate of the Loess Plateau for the long term showed a warmer and dryer trend on the whole [40]. However, in the study, we found that the warming and drying trend had slowed down gradually since 2000 because precipitation showed an increasing trend $\left(2.58 \mathrm{~mm} \mathrm{yr}^{-1}\right)$ while the rate of temperature rise tended to slow down $\left(0.0128^{\circ} \mathrm{C} \mathrm{yr}^{-1}\right)$ (Figure 4). Spatially, there was obvious spatial heterogeneity for the change rate and the trend of precipitation and temperature from 2000 to 2018 in the LP. The annual precipitation change rate was decreasing in the southwest and southeast of the LP and a slowly growing trend in most other regions. In the eastern Shanxi and the central Shaanxi regions, an increasing trend of precipitation was the most obvious and also consistent with the changing trend of vegetation. 

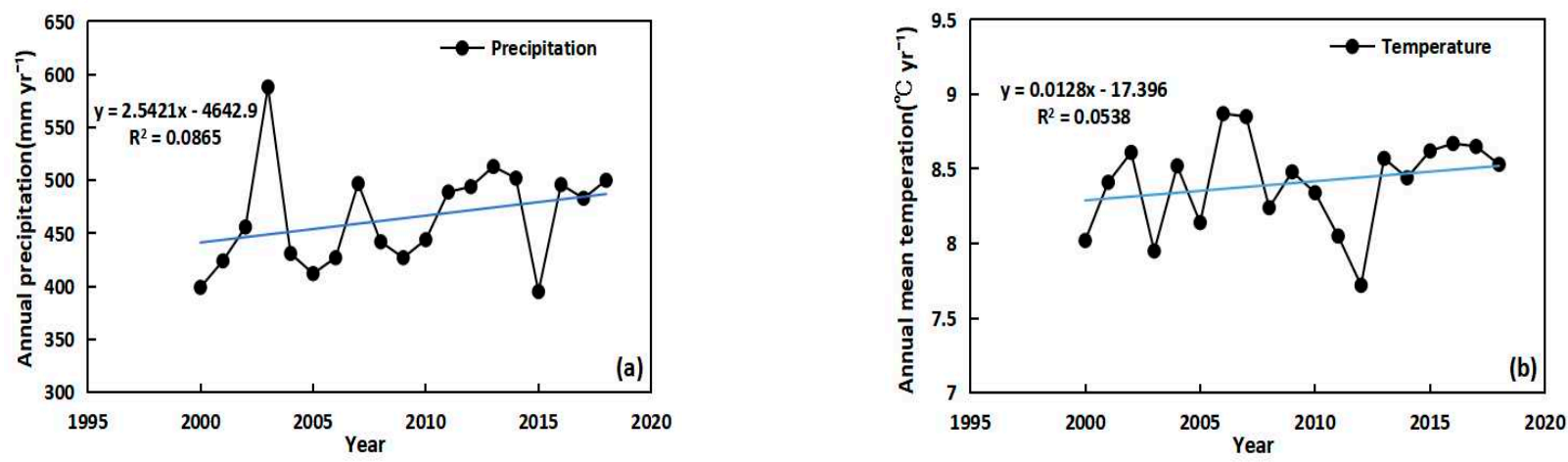

Figure 4. Annual precipitation (a) and annual mean temperature (b) of LP from 2000 to 2018.

\subsubsection{Change in Vegetation}

The "Grain for Green" (GFG) project, which includes many measures of vegetation greening such as converting farmland to forest or grassland, planting trees on barren land, and promoting the natural restoration of the mountains, ensures the continuous improvement of vegetation conditions in the LP.

In the study, the NDVI was used to reveal the changes of historical vegetation from 2000 to 2018 in the LP. There was an obvious increasing trend for the NDVI from 2000 to 2018 as shown in Figure 5a $(0.0078 /$ year $)(p<0.01)$. On the quarterly scale (Figure $5 b)$, the NDVI was also found to increase in all quarters. In the second quarter, the increase of NDVI was the most noticeable, being almost seven times that in the fourth quarter. According to the implementation area of the GFG project, the central and southeastern areas of the LP were the significantly increasing spatial extent for the NDVI. However, in the urban areas, the NDVI still significantly decreased because of urbanization.
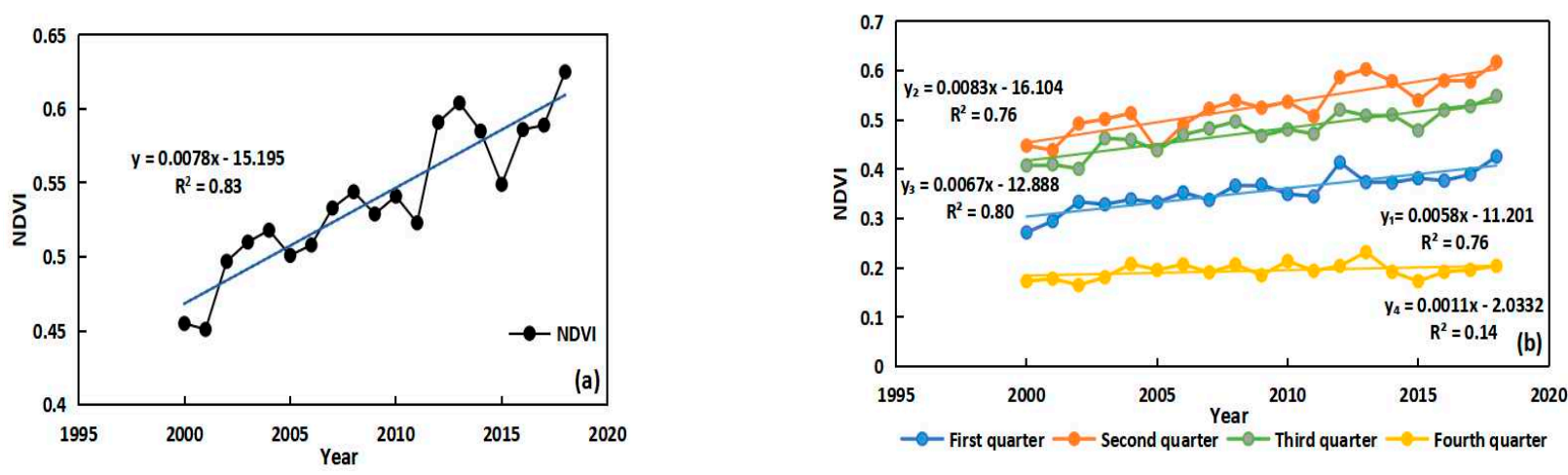

Figure 5. Spatial average trends of (a) annual NDVI and (b) quarterly NDVI scales during 2000-2018.

\subsubsection{Change in ET}

As shown in Figure 6, all the actual ET (ETa) was found to have a significant increasing trend on the annual and quarterly scale. On the annual scale (Figure 6a), the average annual $\mathrm{ET}_{\mathrm{a}}$ increased with the trend of $9.11 \mathrm{~mm} \mathrm{yr}^{-1}$ from 2000 to 2018 in the LP. On the whole, the average annual $\mathrm{ET}_{\mathrm{a}}$ kept a relatively steady increasing trend and the trend of annual $\mathrm{ET}_{\mathrm{a}}$ was roughly consistent with that of the NDVI over the same period. Comparing the trend of average $\mathrm{ET}_{\mathrm{a}}$ and NDVI on the quarterly scale (Figure $6 \mathrm{~b}$ ), the consistency between them was still significantly existent, especially for the second quarter. Additionally, there were other factors influencing the annual $\mathrm{ET}_{\mathrm{a}}$ changes. For instance, in 2004, the rapidly declining annual $\mathrm{ET}_{\mathrm{a}}$ was controlled by the significant decline of precipitation, and the slight increase in annual $\mathrm{ET}_{\mathrm{a}}$ during 2011-2013 may have been the result of the increased precipitation and $\mathrm{ET}_{\mathrm{p}}$. On the quarterly scale, it was noticed that the increasing trend 
of $\mathrm{ET}_{\mathrm{a}}$ in the third quarter (from July to September) was significantly faster than other quarters in one year. In these months, potential water stress may be caused.
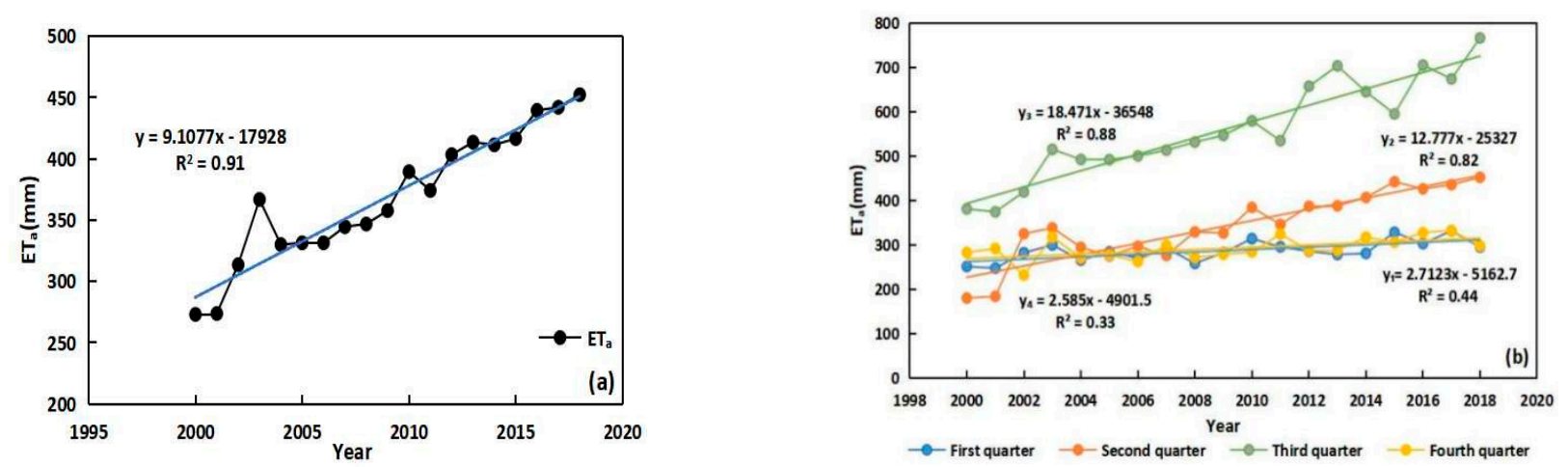

Figure 6. Spatial average trends of (a) annual ETa and (b) quarterly ETa scales during 2000-2018.

Spatially, during 2000-2018, the NDVI showed the trend of increase in most areas in the LP $(93.3 \%)$ and presented a significant increasing trend in the $78.4 \%$ area of the LP (Figure 7a). The $\mathrm{ET}_{\mathrm{a}}$ showed the trend of increasing in most areas of the LP $(99.4 \%)$ and presented a significant increasing trend in the $97.7 \%$ area of the LP (Figure 7b). Obviously, the spatial trends of annual $\mathrm{ET}_{\mathrm{a}}$ were consistent with that of the NDVI, which increased from northwest to southeast. On the contrary, as shown in Figure $7 \mathrm{c}, \mathrm{ET}_{\mathrm{p}}$ in the LP showed a decreasing trend $\left(-4.9 \mathrm{~mm} \mathrm{yr}^{-1}\right)$ and was found to have an obvious complementary relationship with $\mathrm{ET}_{\mathrm{a}}$ in the spatial trend pattern by comparing the spatial pattern of $\mathrm{ET}_{\mathrm{a}}$ trends.
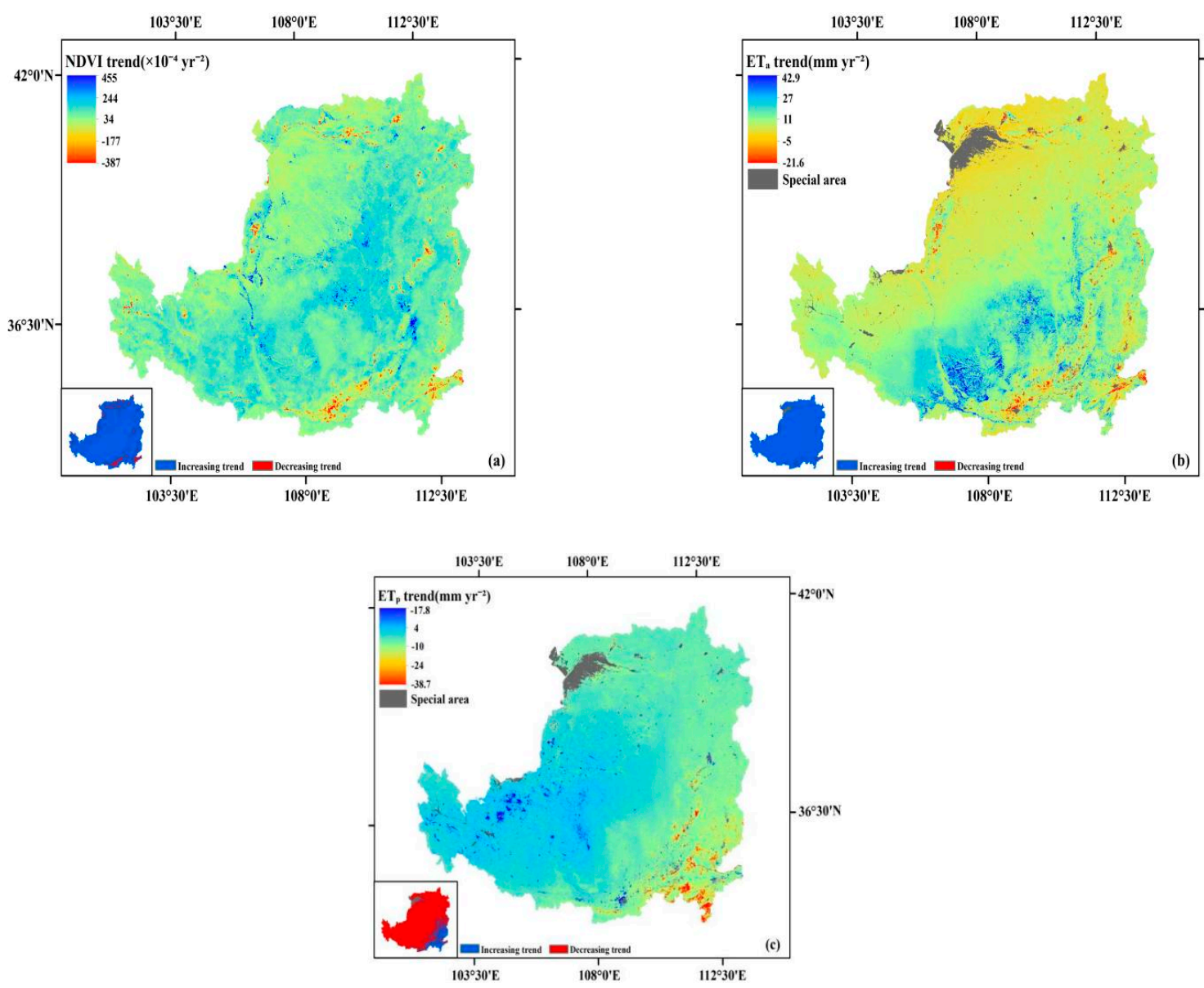

Figure 7. Spatial trends of annual NDVI (a), $\mathrm{ET}_{\mathrm{a}}(\mathbf{b})$, and $\mathrm{ET}_{\mathrm{p}}(\mathbf{c})$ in the LP from 2000 to 2018. 


\subsubsection{Future Change Trend of $\mathrm{ET}_{\mathrm{a}}$}

The mean Hurst exponent of $\mathrm{ET}_{\mathrm{a}}$ in the $\mathrm{LP}$ was 0.46 and the area less than 0.5 accounted for $67.6 \%$, indicating that the reverse characteristics of $\mathrm{ET}_{\mathrm{a}}$ change in the Loess Plateau were stronger than that in the same direction (Figure 8a). The high-value areas of the Hurst index $(\mathrm{H}>0.65)$ were mainly distributed in the middle-south part of the LP, which exhibits that the $\mathrm{ET}_{\mathrm{a}}$ trend in these regions will be strongly consistent with the past trend in the future; the low-value areas of the Hurst exponent $(\mathrm{H}<0.35)$ were mainly distributed in the northeast and northwest of LP, showing that the trend of $\mathrm{ET}_{\mathrm{a}}$ in these regions will be strongly contrary with the past trend in the future; and there were the characteristics of weak co-direction and weak reverse for the trend of $\mathrm{ET}_{\mathrm{a}}$ in other areas in the future. The trend of $\mathrm{ET}_{\mathrm{a}}$ and corresponding Hurst exponent were superposed and coupled to reveal the future trend of $\mathrm{ET}_{\mathrm{a}}$ (Figure $8 \mathrm{~b}$ ). On the whole, $\mathrm{ET}_{\mathrm{a}}$ with a continuously increasing trend was mainly distributed in the northeast of the Loess Plateau, which included the areas of both very low vegetation cover and very high vegetation cover, accounting for $32.1 \%$ area of the LP, while $\mathrm{ET}_{\mathrm{a}}$ with a trend from increase to decrease was mainly distributed in other areas with relatively abundant vegetation, which accounted for $67.2 \%$ area of LP.
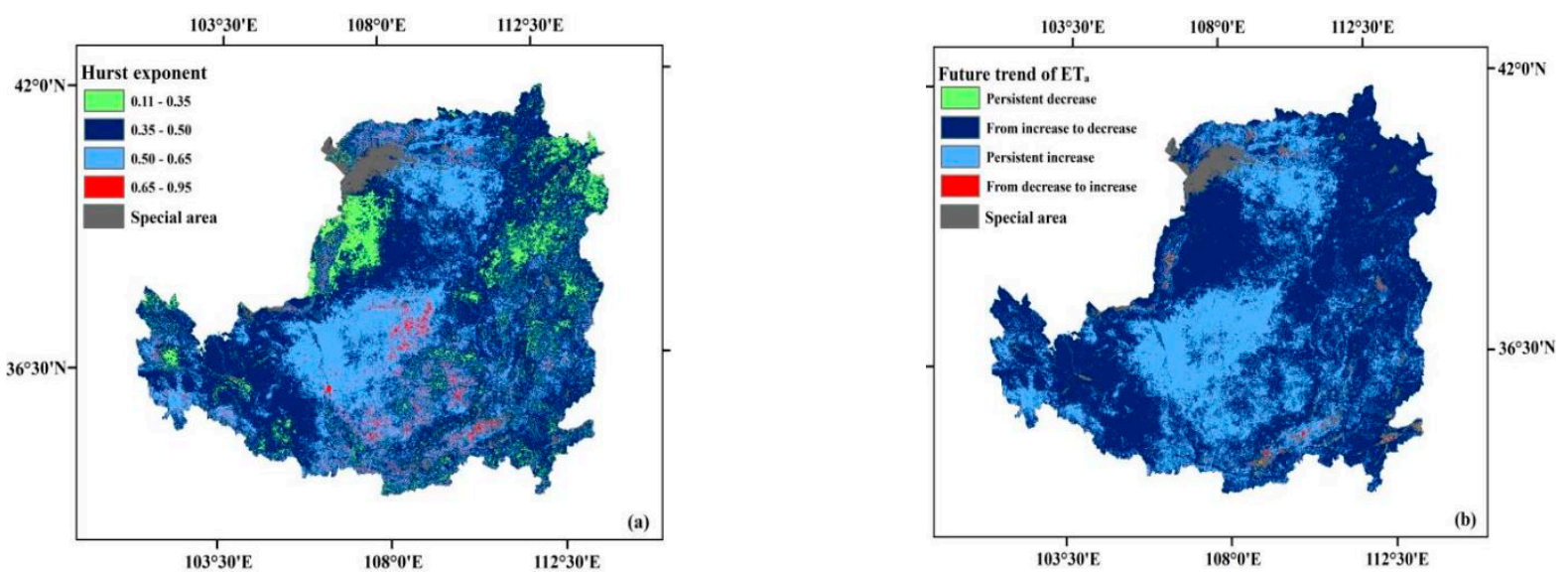

Figure 8. Hurst exponent (a) and future trend of $\mathrm{ET}_{\mathrm{a}}(\mathbf{b})$ in the LP.

\subsection{Dominant Driving Forces in the Changes of Inter-Annual $E T_{a}$}

The fluctuations of annual $\mathrm{ET}_{\mathrm{a}}$ were high (Figure 6a) despite the increasing trend of annual $\mathrm{ET}_{\mathrm{a}}$ on the whole in the LP. Therefore, it was necessary to make clear the dominant forces of $\mathrm{ET}_{\mathrm{a}}$ for the causation of high fluctuations in annual $\mathrm{ET}_{\mathrm{a}}$. The partial correlation analyses on the pixel scale between $\mathrm{ET}_{\mathrm{a}}$ and its driving forces (NDVI, precipitation, and $\mathrm{ET}_{\mathrm{p}}$ ) in the LP were used to reveal the dominant driving forces that controlled the interannual change of $\mathrm{ET}_{\mathrm{a}}$ from 2000 to 2018. As shown in Figure 9a, the spatial consistency for partial correlation coefficients(r) between $\mathrm{ET}_{\mathrm{a}}$ and NDVI was high over the whole study area. The positive correlation areas were distributed on most areas of the LP (97.3\%) and the average value of $r$ was 0.65 on the pixel scale. High $r$ value areas were mainly in the eastern and southern areas of the LP which were abundant in precipitation; low $\mathrm{r}$ value areas were mainly in the northwestern part of the LP where the vegetation was relatively sparse. For the $\mathrm{ET}_{\mathrm{a}}$ and precipitation, their correlations were positive on the whole (Figure 9c). However, the average value of $r$ on the pixel scale was only 0.12 , mainly located in the mid-north part of the LP. The correlation between $\mathrm{ET}_{\mathrm{a}}$ and $\mathrm{P}$ was very weak and even negative in some areas such as the southwest of the LP which is rich in farmland where water pressure was significantly alleviated by artificial irrigation. The partial correlation coefficient values between $\mathrm{ET}_{\mathrm{a}}$ and $\mathrm{ET}_{\mathrm{p}}$ presented conspicuous heterogeneity on the spatial pattern (Figure 9b), where positive correlations were mainly in the southeast part of the LP and negative correlations were mainly in the northwest part of the LP. 

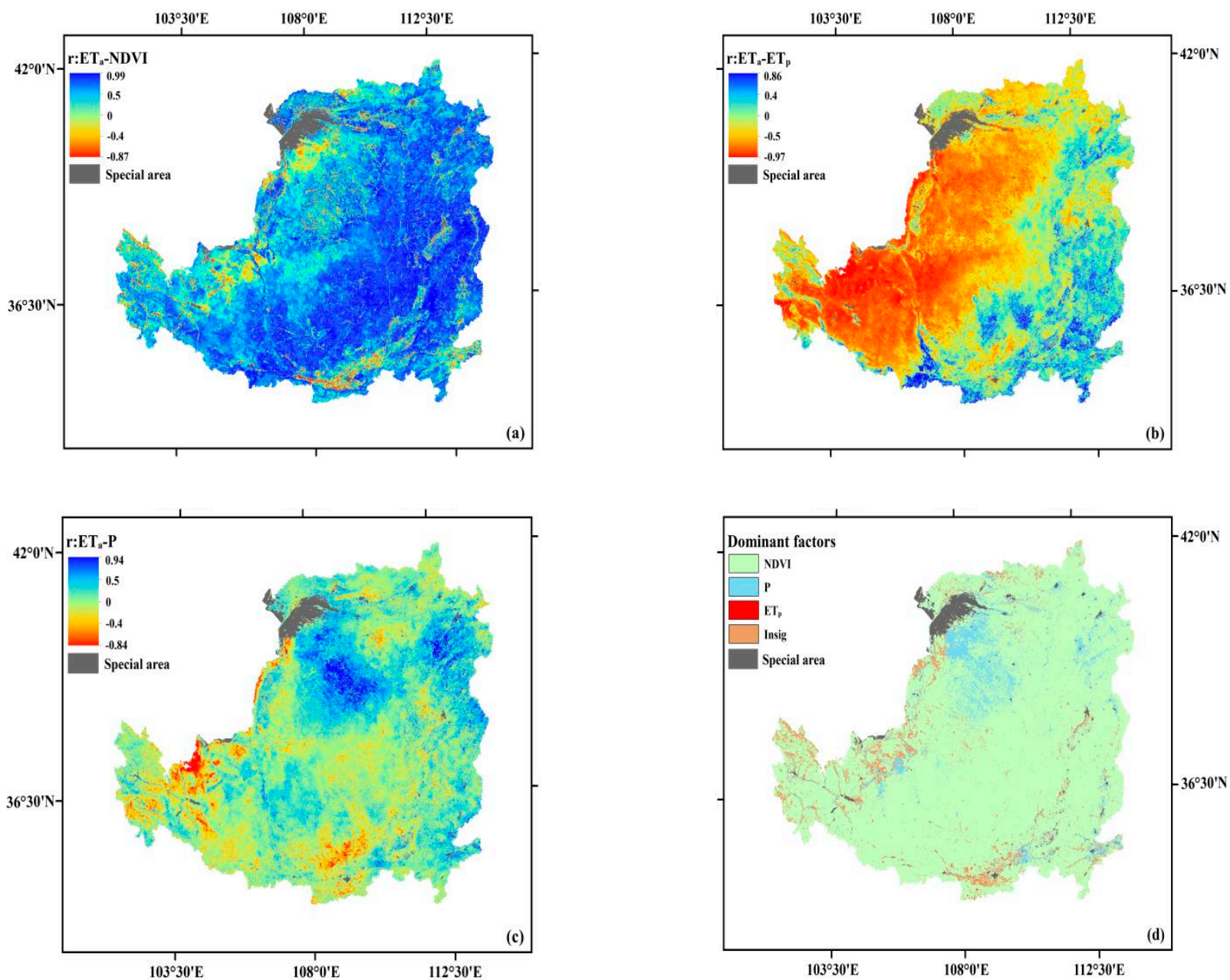

Figure 9. Spatial patterns of the partial correlation coefficient between annual $\mathrm{ET}_{\mathrm{a}}$ and NDVI (a), $\mathrm{ET}_{\mathrm{p}}(\mathbf{b})$, and Precipitation (c); and the dominant driving forces of the inter-annual variation of $\mathrm{ET}_{\mathrm{a}}$ (d) in the LP during 2000-2018.

According to the spatial patterns of partial correlation coefficients, the dominant driving factor of $\mathrm{ET}_{\mathrm{a}}$ changes for each grid cell is shown in Figure $9 \mathrm{~d}$. The inter-annual changes of $\mathrm{ET}_{\mathrm{a}}$ were controlled by the NDVI in most areas of the LP $(87.9 \%)$, while $\mathrm{ET}_{\mathrm{p}}$ controlled that only in $0.1 \%$ of LP areas. For the precipitation, it played a leading role in $6.7 \%$ of the whole study area which was mainly distributed in the northwestern part of the LP.

\subsection{Contributions of Vegetation Greening and Climate Variation to the Trend of $E T_{a}$}

As shown in Figure 10, the spatial heterogeneities in the contribution of the NDVI, $\mathrm{ET}_{\mathrm{p}}$, and precipitation to $\mathrm{ET}_{\mathrm{a}}$ were significant. In general, the $\mathrm{ET}_{\mathrm{a}}$ trend was affected positively by the vegetation greening (Figure 10a). The contribution of the NDVI to the $\mathrm{ET}_{\mathrm{a}}$ trend was relatively high in the southeastern areas of the LP, which was rich in farmlands and woodlands with contribution values of more than $10 \mathrm{~mm} \mathrm{yr}^{-2}$ and even more than $23 \mathrm{~mm} \mathrm{yr}^{-2}$ in some regions. The relatively low contribution values of the NDVI to the $\mathrm{ET}_{\mathrm{a}}$ trend were mainly distributed in the northwestern part of the LP, where the trend of greening was weak and woodlands were dominant with the contribution values of about $3 \mathrm{~mm} \mathrm{yr}^{-2}$. For the precipitation (Figure 10b), climate variation also had an effect on the increase of $\mathrm{ET}_{\mathrm{a}}$. But its contributions were generally low generally, of only $0.52 \mathrm{~mm} \mathrm{yr}^{-2}$. In contrast, $\mathrm{ET}_{\mathrm{p}}$ change had a negative impact on the trend of $\mathrm{ET}_{\mathrm{a}}$ in most areas of the $\mathrm{LP}$ with the average contribution values of $-2.4 \mathrm{~mm} \mathrm{yr}^{-2}$. 

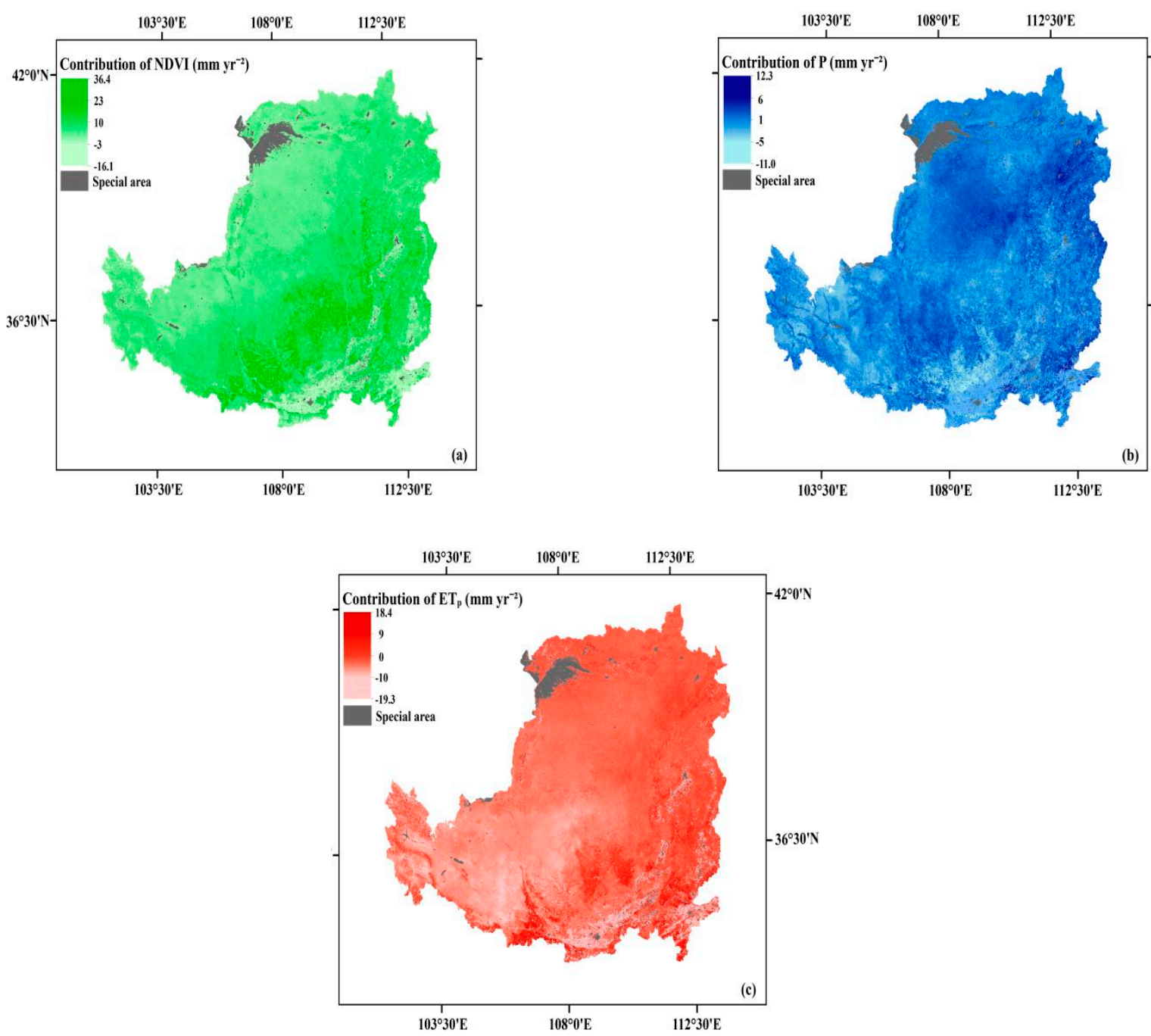

Figure 10. Contributions of vegetation greening (NDVI) (a), precipitation variation $(\mathrm{P})(\mathbf{b})$, and $\mathrm{ET}_{\mathrm{p}}$ variation $(\mathbf{c})$ to the trend of $\mathrm{ET}_{\mathrm{a}}$.

Compared with the value of spatially averaged $\mathrm{ET}_{\mathrm{a}}$ trend $\left(9.11 \mathrm{~mm} \mathrm{yr}^{-2}\right)$, it was clear to find that the relative contributions of $\mathrm{ET}_{\mathrm{p}}, \mathrm{P}$, and NDVI to $\mathrm{ET}_{\mathrm{a}}$ change were $-26.3 \%$ $\left(-2.4 \mathrm{~mm} \mathrm{yr}^{-2}\right), 5.7 \%\left(0.52 \mathrm{~mm} \mathrm{yr}^{-2}\right)$, and $61.4 \%\left(5.59 \mathrm{~mm} \mathrm{yr}^{-2}\right)$ respectively over the whole Loess Plateau. The fact indicated that the vegetation greening represented by the NDVI was the dominant driving force to the long-term trends of $\mathrm{ET}_{\mathrm{a}}$ during 2000-2018 on the Loess Plateau (Figure 10c).

\section{Discussion}

It is generally recognized that $\mathrm{ET}_{\mathrm{p}}$, vegetation condition, and soil water stress (mainly dominated by precipitation) are three main factors that control $\mathrm{ET}_{\mathrm{a}}$ [41]. In the study, we assessed the spatial patterns of ET, NDVI, and precipitation, and analyzed their temporalspatial trends, respectively. From 2000 to 2018, $\mathrm{ET}_{\mathrm{a}}$ in the Loess Plateau showed a significant increasing trend of $9.11 \mathrm{~mm} \mathrm{yr}^{-1}$ with the pattern of low value in the northwest and high value in the southeast. At the same time, NDVI, $\mathrm{P}$ and $\mathrm{ET}_{\mathrm{p}}$ respectively exhibited the trend of $0.0078 \mathrm{yr}^{-1}, 2.58 \mathrm{~mm} \mathrm{yr}^{-1}$, and $-4.9 \mathrm{~mm} \mathrm{yr}^{-1}$, and the trend of inter-annual $\mathrm{ET}_{\mathrm{p}}$ was found to have an obvious complementary relationship with $\mathrm{ET}_{\mathrm{a}}$ in the LP which was coincident with the theory of evapotranspiration complementarity [42]. Considering the trend of NDVI and P in the LP, they are all consistent with that of $\mathrm{ET}_{\mathrm{a}}$ on the whole, and the similar results can also be found in some other studies [26,43]. There is no doubt that the improvement of climatic conditions (an increasing trend in precipitation and tending 
to slow down for the rate of temperature rise) on the LP in the past two decades is a matter worthy of celebration. However, according to the calculation of the Hurst exponent, under the existing change trends of climate and vegetation greening, the $\mathrm{ET}_{\mathrm{a}}$ in a third of the LP will continue to increase in the future and it may aggravate the problem of regional water resources shortage. More attention should be paid to the significant increasing tendency of $\mathrm{ET}_{\mathrm{a}}$ in the LP.

Then, we further researched the causes for the temporal and spatial variation of $\mathrm{ET}_{\mathrm{a}}$. From 2000 to 2018, the contribution of vegetation greening to $\mathrm{ET}_{\mathrm{a}}$ increase reached $61.4 \%$, and vegetation greening was identified as the main cause of the $\mathrm{ET}_{\mathrm{a}}$ trend. At the same time, there were $-26.3 \%$ and $5.7 \%$ of the $\mathrm{ET}_{\mathrm{a}}$ trend being contributed by $\mathrm{ET}_{\mathrm{p}}$ and climate change respectively. These results showed that the reduction of surface albedo and the increase of net radiation absorbed by the surface on the LP with the increase of green leaf area and much deep soil water absorbed by plants during growth can bring a positive effect to $\mathrm{ET}_{\mathrm{a}}$. At the same time, increasing precipitation and temperature also promoted the increase of $\mathrm{ET}_{\mathrm{a}}$. However, our prediction showed that the spatial patterns of annual $\mathrm{ET}_{\mathrm{a}}$ trends on the LP will change a lot and its tendency of decrease in the future will be stronger than that of increase. It indicated that the increase of the amount of actual moisture infiltration into the soil after large-scale vegetation restoration will be higher than the increase of vegetation leaf evaporation caused by the increase of vegetation cover in most of the LP at some point in the future. According to the comparison of spatial patterns between the NDVI and the future trend of $\mathrm{ET}_{\mathrm{a}}$ in the LP, it was found that there are probably three turning points for the trend of $\mathrm{ET}_{\mathrm{a}}$ with the increase of vegetation coverage.

We roughly divide the current vegetation coverage on the LP into three categories: low, medium, and high, and then divide it into four stages to illustrate the corresponding tendency of $\mathrm{ET}_{\mathrm{a}}$ in the future. When the vegetation coverage is lower than the low level, the future $\mathrm{ET}_{\mathrm{a}}$ will decrease; when it is lower than medium grade, the $\mathrm{ET}_{\mathrm{a}}$ will continue to increase; when it is lower than high grade, the future $\mathrm{ET}_{\mathrm{a}}$ will exhibit a decreasing trend; when it is higher than high grade, the future $\mathrm{ET}_{\mathrm{a}}$ will exhibit an increasing trend again. Obviously, in order to play a good role in improving the ecological environment and avoid the conflict between supply and demand of regional water resources, it is the most reasonable afforestation activity to cause the third stage of vegetation coverage which is higher than medium grade and lower than high grade. It exhibits the importance of reasonable scales of vegetation construction. These phenomenons showed the possible existence of the turning point for the $\mathrm{ET}_{\mathrm{a}}$ trend, and the quantitative analysis based on this will be carried out in the future study.

Large-scale vegetation restoration can improve the diversity of the ecosystem and the capacity of water-holding, but the increase of water requirement caused by early vegetation seedling may lead to the change of regional water budget and cause the conflict of potential water demand between the socio-economic system and natural ecosystem. When the actual ET was generally affected by the change of vegetation pattern, the distributive proportion of runoff and $\mathrm{ET}_{\mathrm{a}}$ in precipitation also changed with it. Multi-year averaged $\mathrm{ET}_{\mathrm{a}}$ accounted for nearly $80 \%$ of the corresponding precipitation during 2000-2018 on the LP, and this proportion may continue to increase for a long time according to the significant increasing trend of $\mathrm{ET}_{\mathrm{a}}$ in recent years. As a result, the situation of runoff was worrying. For example, the study of $\mathrm{Li}$ et al. [44] identified that when the vegetation coverage had an increase of $1 \%$ since the 1970s, the runoff coefficient would respectively decrease by 0.0051 and 0.0009 in the semi-dry and semi-humid regions of the LP. For soil water, its responses to afforestation are relatively complex. On the one hand, the increase of vegetation cover will lead to the increase of the soil water storage capacity and surface roughness, and the infiltration of rainstorm events will also be increased accordingly. On the other hand, the increase of vegetation cover can also mean the increase of rainfall interception, which leads to the decrease of net precipitation. In summer, the rainfall in the LP mainly occurs in the form of a rainstorm, so it is speculated that the soil moisture in the corresponding period will increase. However, according to the demonstrations of many studies, the soil desiccation 
on the LP is widespread $[45,46]$, indicating that the additional water consumption of higher vegetation coverage has exceeded the amounts of increased infiltration. In order to maintain both the ecological sustainability and socio-economic benefits, in future reforestation, the threshold of vegetation coverage in the LP should be paid more attention, because the soil water availability actually controlled the degree of vegetation restoration in arid and semiarid regions [47]. Therefore, more reasonable types, densities, and scale of vegetation construction based on the balance of water resources consumption and supply and more adequate utilization of rainfall-runoff in vegetation restoration should be identified to guide the future implementation of ecological restoration strategies.

\section{Conclusions}

This study revealed the spatial-temporal pattern of ET, vegetation greening, and precipitation in the LP from 2000 to 2018 respectively, and identified their spatial-temporal variation characteristics using the univariate linear regression model. Then according to the Hurst exponent, the future trend of $\mathrm{ET}_{\mathrm{a}}$ was predicted. Through partial correlation analysis, the dominant driving factor was ascertained, which controlled the inter-annual change of $\mathrm{ET}_{\mathrm{a}}$ on each pixel. Additionally, contributions of vegetation greening and climate variation to $\mathrm{ET}_{\mathrm{a}}$ trend were quantitatively distinguished on the basis of multiple regression analysis.

During 2000-2018, the average annual $\mathrm{ET}_{\mathrm{a}}$ on the LP exhibited an obvious increasing trend with the value of $9.11 \mathrm{~mm} \mathrm{yr}^{-1}$, and the annual $\mathrm{ET}_{\mathrm{a}}$ trend was dominated by the changes of the third quarterly $\mathrm{ET}_{\mathrm{a}}$. It is noticed that the reverse characteristics of $\mathrm{ET}_{\mathrm{a}}$ change in the Loess Plateau are stronger than that in the same direction, but $\mathrm{ET}_{\mathrm{a}}$ in a third of the LP may continue to increase in the future. Partial correlation analysis indicated that the inter-annual changes of $\mathrm{ET}_{\mathrm{a}}$ were controlled by the NDVI in most areas of the LP $(87.9 \%)$, while $\mathrm{ET}_{\mathrm{p}}$ controlled that only in $0.1 \%$ of areas in the LP. For the precipitation, it controlled that of $\mathrm{ET}_{\mathrm{a}}$ in $6.7 \%$ of the whole study area, which was mainly in the northwestern part of the LP with relatively low precipitation. Over the whole LP, the relative contributions of $\mathrm{ET}_{\mathrm{p}}$, precipitation, and the NDVI to $\mathrm{ET}_{\mathrm{a}}$ trends were $-26.3 \%$ $\left(-2.4 \mathrm{~mm} \mathrm{yr}^{-2}\right), 5.7 \%\left(0.52 \mathrm{~mm} \mathrm{yr}^{-2}\right)$, and $61.4 \%\left(5.59 \mathrm{~mm} \mathrm{yr}^{-2}\right)$, respectively. This fact indicated that the vegetation greening was the dominant driving force to the long-term trend of $\mathrm{ET}_{\mathrm{a}}$ on the LP. In order to keep the sustainable eco-hydrological environment in the LP, we suggest adopting more reasonable types, densities, and scale of vegetation construction based on the balance of water resources consumption and supply, and making more adequate utilization of rainfall-runoff in the future implementation of ecological restoration strategies.

Author Contributions: Conceptualization, S.W., C.C. and Q.D.; methodology, S.W. and C.C.; software, S.W. and C.C.; validation, S.W., C.C. and Q.D.; formal analysis, S.W., C.C. and Q.D.; investigation, S.W., C.C. and Q.D.; resources, S.W., C.C. and Q.D.; data curation, S.W., C.C. and Q.D.; writing—original draft preparation, S.W. and C.C.; writing—review and editing, S.W., C.C. and Q.D.; visualization, S.W., C.C. and Q.D.; supervision, S.W., C.C. and Q.D.; project administration, S.W., C.C. and Q.D.; funding acquisition, C.C. All authors have read and agreed to the published version of the manuscript.

Funding: This research was funded by National Special Project of International Science and Technology Cooperation "Research and Application of Key Technologies to Improve Crop Water Use Efficiency in Arid Area", grant number 2014DFG72150; and NSFC general project "response simulation and sensitivity assessment of agricultural water resources system in northwest arid area under changing environment", grant number 51279166.

Institutional Review Board Statement: Not applicable.

Informed Consent Statement: Not applicable. 
Data Availability Statement: The daily meteorological data are offered by National Earth System Science Data Center of China (http:/ / www.geodata.cn/) in 10 January 2021. The MODIS ET data are obtained from the Level 1 and Atmosphere Archive and Distribution System (LAADS) DAAC of National Aeronautics and Space Administration (NASA) (https:/ / ladsweb.modaps.eosdis.nasa. gov /) in 8 December 2020. The SPOT VEGETATION NDVI data are from Institute of Tibetan Plateau Research, Chinese Academy of Sciences (http:/ / westdc.westgis.ac.cn) in 10 January 2021.

Acknowledgments: The authors are grateful to College of Water Resources and Architecture Engineering, Northwest A\&F University, which kindly provided experimental equipment.

Conflicts of Interest: The authors declare no conflict of interest.

\section{References}

1. Diao, H.; Wang, A.; Yang, H.; Yuan, F.; Guan, D.; Wu, J. Responses of evapotranspiration to droughts across global forests: A systematic assessment. Can. J. For. Res. 2021, 51, 1-9. [CrossRef]

2. Saher, R.; Stephen, H.; Ahmad, S. Urban evapotranspiration of green spaces in arid regions through two estab-lished approaches: A review of key drivers, advancements, limitations, and potential opportunities. Urban Water J. 2021, 18, 115-127. [CrossRef]

3. Ledesma, J.L.; Montori, A.; Altava-Ortiz, V.; Barrera-Escoda, A.; Cunillera, J.; Àvila, A. Future hydrolog-ical constraints of the Montseny brook newt (Calotriton arnoldi) under changing climate and vegetation cover. Ecol. Evol. 2019, 9, 9736-9747. [CrossRef]

4. Shao, R.; Zhang, B.; Su, T.; Long, B.; Cheng, L.; Xue, Y.; Yang, W. Estimating the Increase in Re-gional Evaporative Water Consumption as a Result of Vegetation Restoration over the Loess Plateau, China. J. Geo-Phys. Res. Atmos. 2019, 124, 1178311802. [CrossRef]

5. $\quad$ Feng, X.; Fu, B.; Piao, S.; Wang, S.; Ciais, P.; Zeng, Z.; Lü, Y.; Zeng, Y.; Li, Y.; Jiang, X.; et al. Revegetation in China's Loess Plateau is approaching sustainable water resource limits. Nat. Clim. Chang. 2016, 6, 1019-1022. [CrossRef]

6. Palla, A.; Gnecco, I. A continuous simulation approach to quantify the climate condition effect on the hydrologic performance of green roofs. Urban Water J. 2020, 17, 609-618. [CrossRef]

7. Nazarbakhsh, M.; Ireson, A.M.; Barr, A. Controls on evapotranspiration from jack pine forests in the Boreal Plains Ecozone. Hydrol. Process. 2020, 34, 927-940. [CrossRef]

8. Wohlfart, C.; Liu, G.; Huang, C.; Kuenzer, C. A River Basin over the Course of Time: Multi-Temporal Analyses of Land Surface Dynamics in the Yellow River Basin (China) Based on Medium Resolution Remote Sensing Data. Remote Sens. 2016, 8, 186. [CrossRef]

9. Chen, Y.; Wang, K.; Lin, Y.; Shi, W.; Song, Y.; He, X. Balancing green and grain trade. Nat. Geosci. 2015, 8, 739-741. [CrossRef]

10. Rajib, A.; Kim, I.; Golden, H.; Lane, C.; Kumar, S.; Yu, Z.; Jeyalakshmi, S. Watershed Modeling with Remotely Sensed Big Data: MODIS Leaf Area Index Improves Hydrology and Water Quality Predictions. Remote Sens. 2020, 12, 2148. [CrossRef]

11. Wu, H.; Fu, C.; Wu, H.; Zhang, L. Plant Hydraulic Stress Strategy Improves Model Predictions of the Response of Gross Primary Productivity to Drought Across China. J. Geophys. Res. Atmos. 2020, 125. [CrossRef]

12. He, G.; Zhao, Y.; Wang, J.; Gao, X.; He, F.; Li, H.; Zhai, J.; Wang, Q.; Zhu, Y. Attribution analysis based on Budyko hypothesis for land evapotranspiration change in the Loess Plateau, China. J. Arid Land 2019, 11, 939-953. [CrossRef]

13. Du, X.; Zhao, X.; Zhou, T.; Jiang, B.; Xu, P.; Wu, D.; Tang, B. Effects of Climate Factors and Human Activities on the Ecosystem Water Use Efficiency throughout Northern China. Remote Sens. 2019, 11, 2766. [CrossRef]

14. Yu, D.; Li, X.; Cao, Q.; Hao, R.; Qiao, J. Impacts of climate variability and landscape pattern change on evapotranspiration in a grassland landscape mosaic. Hydrol. Process. 2019, 34, 1035-1051. [CrossRef]

15. Pradhan, N.; Floyd, I.; Brown, S. Satellite Imagery-Based SERVES Soil Moisture for the Analysis of Soil Moisture Initialization Input Scale Effects on Physics-Based Distributed Watershed Hydrologic Modelling. Remote Sens. 2020, 12, 2108. [CrossRef]

16. Xu, Y.D.; Fu, B.J.; He, C.S. Assessing the hydrological effect of the check dams in the Loess Plateau, China, by model simulations. Hydrol. Earth Syst. Sci. 2013, 17, 2185-2193. [CrossRef]

17. Waseem, M.; Kachholz, F.; Klehr, W.; Traenckner, J. Suitability of a Coupled Hydrologic and Hydraulic Model to Simulate Surface Water and Groundwater Hydrology in a Typical North-Eastern Germany Lowland Catchment. Appl. Sci. 2020, 10, 1281. [CrossRef]

18. Luo, Y.; Yang, Y.; Yang, D.; Zhang, S. Quantifying the impact of vegetation changes on global terrestrial run-off using the Budyko framework. J. Hydrol. 2020, 590, 125389. [CrossRef]

19. Zhang, X.; Dong, Q.; Cheng, L.; Xia, J. A Budyko-based framework for quantifying the impacts of aridity index and other factors on annual runoff. J. Hydrol. 2019, 579, 124224. [CrossRef]

20. Zhang, S.; Yang, Y.; McVicar, T.R.; Zhang, L.; Yang, D.; Li, X. A proportionality-based multi-scale catch-ment water balance model and its global verification. J. Hydrol. 2020, 582, 124446. [CrossRef]

21. Rasouli, K.; Pomeroy, J.W.; Whitfield, P.H. Are the effects of vegetation and soil changes as important as climate change impacts on hydrological processes? Hydrol. Earth Syst. Sci. 2019, 23, 4933-4954. [CrossRef]

22. Bai, M.; Shen, B.; Song, X.; Mo, S.; Huang, L.; Quan, Q. Multi-Temporal Variabilities of Evapotranspira-tion Rates and Their Associations with Climate Change and Vegetation Greening in the Gan River Basin, China. Water 2019, 11, 2568. [CrossRef] 
23. Huang, Z.; Liu, Y.F.; Cui, Z.; Liu, Y.; Wang, D.; Tian, F.P.; Wu, G.L. Natural grasslands maintain soil water sus-tainability better than planted grasslands in arid areas. Agric. Ecosyst. Environ. 2019, 286, 106683. [CrossRef]

24. Zhao, J.; Chen, X.; Zhang, J.; Zhao, H.; Song, Y. Higher temporal evapotranspiration estimation with improved SEBS model from geostationary meteorological satellite data. Sci. Rep. 2019, 9, 14981. [CrossRef] [PubMed]

25. Hagg, W.; Mayr, E.; Mannig, B.; Reyers, M.; Schubert, D.; Pinto, J.G.; Peters, J.; Pieczonka, T.; Juen, M.; Bolch, T.; et al. Future Climate Change and Its Impact on Runoff Generation from the Debris-Covered Inylchek Glaciers, Central Tian Shan, Kyrgyzstan. Water 2018, 10, 1513. [CrossRef]

26. Yang, L.; Feng, Q.; Adamowski, J.F.; Alizadeh, M.R.; Yin, Z.; Wen, X.; Zhu, M. The role of cli-mate change and vegetation greening on the variation of terrestrial evapotranspiration in northwest China's Qilian Mountains. Sci. Total Environ. 2021, 759, 143532. [CrossRef]

27. Jung, M.; Reichstein, M.; Ciais, P.; Seneviratne, S.I.; Sheffield, J.; Goulden, M.L.; Bonan, G.; Cescatti, A.; Chen, J.; De Jeu, R.; et al. Recent decline in the global land evapotranspiration trend due to limited moisture supply. Nature 2010, 467, 951-954. [CrossRef]

28. Kim, H.W.; Hwang, K.; Mu, Q.; Lee, S.O.; Choi, M. Validation of MODIS 16 global terrestrial evapo-transpiration products in various climates and land cover types in Asia. KSCE J. Civ. Eng. 2012, 16, 229-238. [CrossRef]

29. Liu, S.; Xu, Z.; Zhu, Z.; Jia, Z.; Zhu, M.; Liu, S.; Xu, Z.; Zhu, Z.; Jia, Z.; Zhu, M. Measurements of evapotranspiration from eddy-covariance systems and large aperture scintillometers in the Hai River Basin, China. J. Hydrol. 2013, 487, 24-38. [CrossRef]

30. Monteith, J.L. Environmental Control of Plant Growth; Academie Press: New York, NY, USA, 1963; pp. 95-112.

31. Mandelbrot, B.B.; Riedi, R.H. Inverse Measures, the Inversion Formula, and Discontinuous Multifractals. Adv. Appl. Math. 1997, 18, 50-58. [CrossRef]

32. Raja, N.B.; Aydin, O.; Türkoğlu, N.; Çiçek, I. Space-time kriging of precipitation variability in Turkey for the period 1976-2010. Theor. Appl. Clim. 2017, 129, 293-304. [CrossRef]

33. Qiu-Hao, H.; Yun-Long, C. Assessment of karst rocky desertification using the radial basis function network model and GIS technique: A case study of Guizhou Province, China. Environ. Earth Sci. 2006, 49, 1173-1179. [CrossRef]

34. Bartier, P.M.; Keller, C.P. Multivariate interpolation to incorporatethematic surface data using inverse distance weighting (IDW). Comput. Geosci. 1996, 22, 795-799. [CrossRef]

35. Su, S. Flexible parametric quantile regression model. Stat. Comput. 2014, 25, 635-650. [CrossRef]

36. Tatli, H. Detecting persistence of meteorological drought via the Hurst exponent. Meteorol. Appl. 2015, 22, 763-769. [CrossRef]

37. Gentilucci, M.; Barbieri, M.; Burt, P. Climatic Variations in Central Italy. Water 2018, 10, 1104. [CrossRef]

38. Zhang, S.H.; Liu, S.X.; Mo, X.G.; Shu, C.; Sun, Y.; Zhang, C. Assessing the Impact of Climate Change on Reference Evapotranspiration in Aksu River Basin. J. Geogr. Sci. 2011, 21, 609-620. [CrossRef]

39. Yue, P.; Zhang, Q.; Zhang, L.; Li, H.; Yang, Y.; Zeng, J.; Wang, S. Long-term variations in energy parti-tioning and evapotranspiration in a semiarid grassland in the Loess Plateau of China. Agric. For. Meteorol. 2019, 278, 107671. [CrossRef]

40. Wu, Z.; Yu, L.; Du, Z.; Zhang, H.; Fan, X.; Lei, T. Recent changes in the drought of China from 1960 to 2014. Int. J. Clim. 2019, 40, 3281-3296. [CrossRef]

41. Lettenmaier, D.P.; Famiglietti, J.S. Hydrology-Water from on high. Nature 2006, 444, 562-563. [CrossRef] [PubMed]

42. Yang, L. Spatiotemporal Characteristics of Evapotranspiration over the Qinghai Ti-bet Plateau Based on the Principle of Generalized Complementarity. Front. Earth Sci. 2020, 10, 999.

43. Li, S.; Liang, W.; Fu, B.; Lü, Y.; Fu, S.; Wang, S.; Su, H. Vegetation changes in recent large-scale ecological restoration projects and subsequent impact on water resources in China's Loess Plateau. Sci. Total Environ. 2016, 569, 1032-1039. [CrossRef]

44. Gao, G.; Fu, B.; Wang, S.; Liang, W.; Jiang, X. Determining the hydrological responses to climate variability and land use/cover change in the Loess Plateau with the Budyko framework. Sci. Total Environ. 2016, 557-558, 331-342. [CrossRef]

45. Shao, M.; Wang, Y.; Xia, Y.; Jia, X. Soil Drought and Water Carrying Capacity for Vegetation in the Critical Zone of the Loess Plateau: A Review. Vadose Zone J. 2018, 17, 170077. [CrossRef]

46. Huang, F.; Chunyu, X.; Zhang, D.; Chen, X.; Ochoa, C.G. A framework to assess the impact of ecological water conveyance on groundwater-dependent terrestrial ecosystems in arid inland river basins. Sci. Total Environ. 2020, 709, 136155. [CrossRef]

47. Wang, C.; Wang, S.; Fu, B.; Lü, Y.; Liu, Y.; Wu, X. Integrating vegetation suitability in sustainable revegetation for the Loess Plateau, China. Sci. Total Environ. 2021, 759, 143572. [CrossRef] [PubMed] 